\title{
'Normal' vaginal microbiology of women of childbearing age in relation to the use of oral contraceptives and vaginal tampons
}

\author{
C. A. MORRIS AND DELIA F. MORRIS \\ From the Bristol Laboratory of the Public Health Laboratory Service
}

SYNOPSIS The vaginal microbiology of women attending a family planning clinic was found to be unrelated to the use of oral contraceptives and vaginal tampons.

Beta haemolytic streptococci isolated from this 'normal' population were compared with those from 1,104 women attending general practitioners complaining of vaginal discharge. There is a caution regarding the indications for antibiotic therapy.

Observations were made on the effects of contamination of vaginal swabs with yeasts and $\beta$-haemolytic streptococci from the vulva. The persistent character of the vaginal flora over a six month period is described.

Reports of monilial vulvo-vaginitis associated with oral contraceptives (Yaffee and Grots, 1965; Porter and Lyle, 1966; Catterall, 1966) indicate that artificial alterations in the normal anatomy and physiology of the female genital tract may introduce a hazard to the patient. The indiscriminate use of antibiotics to treat vaginitis associated with bacteria of dubious pathogenicity has been said by Morison (1966) to predispose to 'abacterial vaginitis'. These reports prompted this investigation, which was undertaken to establish a base line for variations in the 'normal' vaginal flora and to measure the influence on it of oral contraceptives and vaginal tampons.

\section{MATERIAL AND METHODS}

Swabs of vaginal secretions were examined from a series of 291 non-pregnant patients attending a family planning clinic between December 1965 and July 1966. Patients were excluded from the study only if they had a contraceptive cap in situ or were menstruating. Up to 10 women were examined at a clinic but when a busy session prohibited the examination of all eligible patients only the first few attending sequentially were included. No patient was under treatment for a discharge.

From each patient three vaginal swabs were taken through a sterile speculum or a glass funnel before a vaginal examination was performed. The first two, charcoal-impregnated swabs, were broken into Stuart's ${ }^{1}$ Bath Branch, Family Planning Association. Received for publication 24 January 1967. thioglycollate transport medium and into a modified Feinberg trichomonas medium (Stenton, 1957); a thir but plain swab was used to prepare wet films and smears for staining by Gram's method.

Five culture plates were inoculated with the swab? from transport medium within four hours of sampling and were examined after 36,48 , and 72 hours' incubation at $37^{\circ} \mathrm{C}$. Two of these plates, $10 \%$ oxalated horse bloof in Oxoid no. 2 blood agar base and MacConkey's lactose bile salt agar, were incubated aerobically; two, horse blood agar and crystal violet blood agar, anaerobically and the heated horse blood agar (chocolate agar) plate in a candle jar. The 'chocolate agar' was a modification of the medium described by Cooper, Mayr-Harting, and McLachlan (1950) in which oxalated horse blood was substituted for rabbit blood. Trichomonas cultures were continued at $36^{\circ} \mathrm{C}$. for a week and examined on alternater days. The swab from transport medium was places. finally in a tube of $3 \%$ glucose broth containing $0.05 \mathrm{mg}$. chloramphenicol per millilitre which was maintained aP room temperature for a week before the broth was examined for the presence of yeasts.

These methods, apart from the yeast enrichment culture and prolonging the plate incubations for an additionat 24 hours, are those used for the examination of routin\& vaginal swabs submitted to this laboratory.

The bacterial flora was defined by standard bacterio logical methods and yeasts were identified by their ability to produce germ tubes in serum at $37^{\circ} \mathrm{C}$. (Taschd $\stackrel{\circ}{\circ}$ jian, Burchall, and Kozinn, 1960), filament and chlamydo $\frac{\mathbb{N}}{\mathrm{N}}$ spore formation on corn meal agar, and zymogramid patterns.

In addition to examining the vaginal flora, $162^{\circ}$ patients were investigated for the presence of yeasts an $\delta$ 636 
$\beta$-haemolytic streptococci on the vulva; swabs from the vulva were plated onto crystal violet blood agar and incubated in glucose chloramphenicol broth.

\section{RESULTS}

THE POPULATION Of the 291 women examined, nearly three quarters $(72 \%)$ belonged to social classes II or III (Census, 1961). The ages ranged from 18 to 45 , with $75 \%$ aged 20 to 35 . Thirty women were single and 261 married. One in four was nulliparous whereas $56 \%$ had had two to five pregnancies. Oral contraceptives were used by 104 patients, two-thirds for a period exceeding six months. Vaginal tampons were used by 184 women (Table I).

Cervical erosions were observed in $51 \%$ of patients taking oral contraceptives but in only $33 \%$ of women who were not on hormone treatment $\left(\chi^{2}=\right.$ 8.87, $\mathrm{P}<0.01)$.

Specimens were taken at any stage of the menstrual cycle with the result that nearly $30 \%$ were taken in each of the last three weeks of the cycle.

DIRECT SMEARS Two patients had purulent vaginal secretions, both associated with Trichomonas vaginalis infection; all other specimens were of a predominant epithelial type with few or no leucocytes.

CULTURE RESULTS The vaginal flora in relation to
TABLE I

VAGINAL FLORA SURVEY IN A FAMILY PLANNING CLINIC POPULATION

\begin{tabular}{|c|c|c|c|c|c|}
\hline & & $P a t$ & & $\begin{array}{l}\text { Perce } \\
\text { Popu }\end{array}$ & $\begin{array}{l}\text { atage } \\
\text { ation }\end{array}$ \\
\hline $\begin{array}{l}\text { Total population } \\
\text { Marital status Sing }\end{array}$ & & & $\begin{array}{r}291 \\
30 \\
261\end{array}$ & & $\begin{array}{l}100 \\
10 \cdot 3 \\
89 \cdot 7\end{array}$ \\
\hline $\begin{array}{c}\text { Contraceptive metho } \\
\text { (a) Hormonal } \\
\end{array}$ & $\begin{array}{l}\text { Idiol }^{1} \\
\text { ovlar }^{2} \\
\text { len }\end{array}$ & $\begin{array}{l}40 \\
25 \\
25 \\
14\end{array}$ & 104 & $\begin{array}{r}13 \cdot 7 \\
8 \cdot 6 \\
8 \cdot 6 \\
4 \cdot 8\end{array}$ & 35.7 \\
\hline $\begin{array}{l}\text { (b) No method } \\
\text { (c) Non-hormonal }\end{array}$ & $\begin{array}{l}\text { Mechanical } \\
\text { Chemical } \\
\text { Mechanical and } \\
\text { chemical }\end{array}$ & $\begin{array}{r}83 \\
49 \\
3 \\
52\end{array}$ & 187 & $\begin{array}{r}28 \cdot 5 \\
16 \cdot 8 \\
1 \cdot 2 \\
17 \cdot 8\end{array}$ & $64 \cdot 3$ \\
\hline Sanitary method & $\begin{array}{l}\text { apons } \\
\text { rels }\end{array}$ & & $\begin{array}{l}184 \\
107\end{array}$ & & $\begin{array}{l}63 \cdot 2 \\
36 \cdot 8\end{array}$ \\
\hline
\end{tabular}

${ }^{1}$ Lyndiol, $5 \mathrm{mg}$. lynoestrenol $+0 \cdot 15 \mathrm{mg}$. mestranol

Anovlar, $4 \mathrm{mg}$. norethisterone acetate $+0.05 \mathrm{mg}$. ethinyloestradiol 'Ovulen, $1 \mathrm{mg}$. ethynodiol diacetate $+0 \cdot 1 \mathrm{mg}$. mestranol

contraceptive and sanitary method is summarized in Table II. Isolations of two different species of pseudomonads and single strains of a klebsiella and a bacillus are not included as they do not warrant subdivision. A heterogeneous group of 11 catalasenegative microaerophilic Gram-variable bacilli is also not tabulated.

TABLE II

VAGINAL FLORA OF FAMILY PLANNING PATIENTS IN RELATION TO CONTRACEPTIVE AND SANITARY METHODS

Isolation ( $\%$ ) of Patients in Each Category

\begin{tabular}{|c|c|c|c|c|}
\hline \multirow{2}{*}{$\begin{array}{l}\text { Total } \\
\text { Population }\end{array}$} & \multicolumn{2}{|c|}{ Oral Contraceptives } & \multicolumn{2}{|c|}{ Vaginal Tampons } \\
\hline & Used & Not Used & Used & Not Used \\
\hline
\end{tabular}

A Culture Classification

Abundant mixed flora ${ }^{1}$

Bacteria of faecal origin ${ }^{2}$

$24 \cdot 4$

$16 \cdot 8$

$23 \cdot 1$

$12 \cdot 5$

$1 \cdot 4$
$21 \cdot 3$

$21 \cdot 3$
$49 \cdot 1$

Clostridium welchi

Corynebacteria

Lactobacilli (predominant)

Staphylococci and micrococci

Staphylococcus pyogenes

Streptococci

Beta haemolytic

Strep. faecalis

Other aerobic

Anaerobic

Bacteroides

Escherichia coli

Proteus

C Yeasts

Candida albicans

Other yeasts
$2 \cdot 7$

$10.9 \quad 9.7$

$\begin{array}{rr}9.6 & 7 \cdot 7\end{array}$

$18 \cdot 2 \quad 22 \cdot 1$

$4.8 \quad 3.8$

$\begin{array}{ll}5 \cdot 8 & 3.8 \\ 2 \cdot 7 & 1.0\end{array}$

$10 \cdot 7$

6.9 $\begin{array}{ll}1.0 & 0.0\end{array}$
$25 \cdot 0$

$19 \cdot 3$

$23 \cdot 4$

$14 \cdot 1$

$1 \cdot 6$
$22 \cdot 4$

$22 \cdot 4$
$47 \cdot 0$

$37 \cdot 4$

1.6

$11 \cdot 8$

$10 \cdot 7$

$16 \cdot 0$

$5 \cdot 3$

1.6
6.9

$3 \cdot 7$

$9 \cdot 1$

$8 \cdot 5$

${ }^{1}$ Two or more species, with no one species forming more than $60 \%$ colonies isolated

${ }^{2}$ Sum of Strep. faecalis, Esch. coli and $\mathrm{Cl}$. welchii

$380 \%$ or more of colonies isolated 
TABLE III

ISOLATIONS OF BETA HAEMOLYTIC STREPTOCOCCI IN THE VAGINA FROM FAMILY PLANNING CLINIC AND GENERAL PRACTICE PATIENTS

Family Planning Clinic General (291 Patients)

Practice

(1,104 Patients)

\begin{tabular}{lllll} 
Lancefield's Group & $\begin{array}{l}\text { Total No. of } \\
\text { Strains }\end{array}$ & $\begin{array}{l}\text { No. of Strains } \\
\text { in Profuse } \\
\text { Growth }\end{array}$ & $\begin{array}{l}\text { No. of } \\
\text { Strains }\end{array}$ \\
\hline Total & $32(10.9 \%)$ & $12(4.0 \%)$ & $66(6.0 \%)$ \\
A & $1(0.3 \%)$ & $1(0.3 \%)$ & $15(1.4 \%)$ \\
B & $18(6.2 \%)$ & $9(3.1 \%)$ & $20(1.8 \%)$ \\
C & $2(0.7 \%)$ & $-1(0.3 \%)$ & $21(1.9 \%)$ \\
D & $10(3.4 \%)$ & $10.5 \%)$ \\
F & $1(0.3 \%)$ & $1(0.3 \%)$ & $1(0.1 \%)$ \\
G & $1(0.3 \%)$
\end{tabular}

The serological groups of $\beta$-haemolytic streptococci are shown in Table III.

Eighteen per cent of patients harboured vaginal yeasts of which just over half $(10.7 \%)$ were Candida albicans (Table IIC); other yeasts isolated included three strains of Torulopsis glabrata, two of Saccharomyces cerevisiae, and 15 Candida species including C. krusei, C. parakrusei, C. pseudotropicalis, and $C$. guilliermondi. The mode of primary isolation of yeasts is given in Table IV.

\section{TABLE IV}

FACILITY OF YEAST DETECTION AS A QUANTTTATIVE ESTIMATE OF YEASTS FROM THE VAGINA OF FAMILY PLANNING CLINIC PATIENTS

\begin{tabular}{|c|c|c|c|c|c|c|}
\hline \multirow{3}{*}{$\begin{array}{l}\text { Contra- } \\
\text { ceptive }\end{array}$} & \multirow{3}{*}{$\begin{array}{l}\text { No. of } \\
\text { Patients }\end{array}$} & \multirow{3}{*}{ Yeast } & \multicolumn{4}{|c|}{ Method of Identification } \\
\hline & & & \multicolumn{2}{|c|}{ Direct Microscopy ${ }^{1}$} & \multicolumn{2}{|c|}{ Culture } \\
\hline & & & $\begin{array}{l}\text { Blasto- } \\
\text { spore }\end{array}$ & Mycelium & Direct & $\begin{array}{l}\text { Enrich- } \\
\text { ment }\end{array}$ \\
\hline \multirow[t]{2}{*}{ Oral } & 104 & $\begin{array}{c}\text { C. albicans } \\
14\end{array}$ & 7 & 4 & 11 & 3 \\
\hline & & Other 4 & 3 & 2 & 3 & 1 \\
\hline \multirow[t]{2}{*}{ Non-oral } & 1187 & $\begin{array}{c}\text { C. albicans } \\
17\end{array}$ & 7 & 4 & 9 & 8 \\
\hline & & Other 16 & 7 & 2 & 10 & 6 \\
\hline
\end{tabular}

Wet preparations and stained films

Clostridium welchii was isolated from four specimens and always as occasional colonies in a mixed culture.

Staphylococcus pyogenes was recovered in profuse growth from one specimen only.

Escherichia coli was isolated more often from samples taken during the first half of the menstrual cycle $(8.6 \%)$ than the second half $(4 \cdot 3 \%)$ whereas Streptococcus faecalis and corynebacteria were isolated with uniform frequency at all stages of the cycle.
Trichomonas vaginalis was found in three patients, two in association with symptoms. The third patiento had no symptoms and the protozoa were demonstrated by culture only.

Mycoplasma sp. are not recorded in Table II Colony forms morphologically consistent with pleuropneumonia-like organisms were present on impression smears of some cultures but it was not found practicable to record their numbers in mixedes culture with any certainty. To assess accurately the prevalence of mycoplasmas will require a specialinvestigation.

SWABS FROM THE VULVA Examination of swabs from the vagina and vulva of 162 patients showed that $16.6 \%$ of these women had yeasts $(10.5 \% \text { C. albicans })^{\oplus}$ at both sites. An additional $5 \%$ of patients harbourede yeasts $(1 \cdot 2 \%$ C. albicans $)$ on the vulva but not in theo vagina. Beta haemolytic streptococci were present in? both sites in $9.8 \%$ of patients, with an additional $3 \%$ demonstrated from the vulva.

RE-EXAMINATIONS Nineteen of 22 patients re examined six months after their first visit showed no change of flora; this group included two patients with $C$. albicans, one with $S$. cerevisiae, and one with group B streptococci present on both occasions Fifteen patients, including seven who had starteco taking oral contraceptives after their first visit 2 retained a flora in which lactobacilli predominated? Three patients showed a change, losing a group $A^{3}$ and group $\mathrm{C}$ streptococcus and a pseudomonad respectively.

\section{DISCUSSION}

The striking feature of the results is the similarity of the vaginal flora irrespective of sanitary and contraceptive methods. Although patients taking orap contraceptives had a significantly higher incidence of cervical erosions than that among patients not of hormones, this was not associated with alteration in the vaginal flora or with an increased incidence of a discharge. Since these two groups of patients were not fully comparable for age and parity and the type of erosion was not recorded, it should not be inferred from this study that oral contraceptives necessarily predisposed these patients to cervicas erosions.

The insertion of tampons is likely to carry bacterig into the vagina from the vulva and perianal ski but Table IIA shows that patients who used tampon were not specially liable to have a mixed bacteria flora or to carry faecal organisms in the vagina Since most specimens were taken more than a week 
after the first day of the last menstrual period, it may be that usually the vaginal lactobacillary flora was re-established and contaminants displaced before samples were collected.

The figures for $\beta$-haemolytic streptococci warrant further analysis and comment because of the high frequency with which they occurred in profuse culture (Table III). Nearly $11 \%$ of patients harboured $\beta$-haemolytic streptococci in the vagina. The predominance of group B and group D strains is consistent with their acid-resistant properties relative to the other groups. If these patients had been treated because of the presence of numerous streptococci without prior determination of the serological group, $3 \%$ of patients would have received antibiotics for group $B$ infections which were presumably of no significance. That this is relevant to the routine examination of vaginal swabs is shown by the similar incidence of $1.8 \%$ of group B streptococci (profuse growth) isolated in our laboratory from 1,104 vaginal swabs submitted from patients complaining of a discharge. In view of reports of fatal acute and subacute endocarditis caused by haemolytic streptococci other than group A (Rosenthal and Stone, 1940; Ramsay and Gillespie, 1941), treatment may be indicated for antenatal and puerperal patients and women with cardiac abnormalities in whom any haemolytic streptococcus may be a potential pathogen.

Liston and Cruickshank (1940) recorded an increased incidence of vaginal moniliasis occurring in pregnancy; this predisposition has been ascribed (Davis and Pearl, 1938) to glycogen deposition in the vaginal epithelium, a phenomenon said by Cruickshank and Sharman (1934) to be under the influence of oestrogen. Porter and Lyle (1966) described difficulties in curing patients of $C$. albicans vulvovaginitis when the patients were using oral contraceptives. Three of their 13 patients taking Enovid (norethynodrel with mestranol) failed to respond to treatment until taken off the 'pill'. Their observations are supported by those of Yaffee and Grots (1965) and Catterall (1966).

The incidence of $13.5 \%$ C. albicans (Table IIC) in clinic patients using oral contraceptives is not significantly higher than that of $9.1 \%$ among patients not on hormones. Three of the 30 single women had latent $C$. albicans infection. Neither marital state nor parity appeared to influence the frequency of Candida isolations.

Oestrogen supplementation occurring in a patient taking oral contraceptives may promote yeast multiplication in the vagina; this, however, may be prevented from reaching a pathological and symptomatic level by the monthly withdrawal of the 'pill' to allow 'menstruation'. If this is so, then a measure of the enhancement of yeast multiplication is the ease with which yeasts are found by direct microscopy and culture as compared with enrichment culture alone. Table IV records the ease with which yeasts were found; the difference between those using and not using the 'pill' is not significant.

In this study, patients using oral contraceptives showed no significantly increased incidence of C. albicans and did not have a more severe infection once yeasts had reached the vagina. All these patients were treated with combinations of oestrogens and progestogens; the particular preparation prescribed was chosen, after assessment of the individual, as the one least likely to impose side effects. Lyndiol is expected to exert a predominant oestrogenic-like effect and Anovlar and Ovulen are predominantly progesterone-like in action.

The persistence over a six-month period of $S$. cerevisiae in the vagina of a patient with a chronic low-grade discharge deserves note. This strain grew well at $37^{\circ} \mathrm{C}$. It may have originated from the intestine but in this patient was never associated with bacteria of faecal origin.

Asymptomatic trichomoniasis occurred in one patient. Direct films of the vaginal secretions from this patient showed numerous epithelial cells with only occasional leucocytes and gave no indication of the underlying infection. Retrospective re-examination of smears failed to demonstrate the protozoon.

A general practitioner may have difficulty in obtaining samples of vaginal secretions uncontaminated by vulval flora. Comparison of the numbers of yeasts and $\beta$-haemolytic streptococci isolated from paired vulval and vaginal swabs suggests that accidental contamination from the vulva may increase the isolations of commensal yeasts and $\beta$-haemolytic streptococci but only rarely of $C$. albicans. Group A streptococci were present on the vulva of one patient but not demonstrated in the vagina.

Difficulties in gauging the significance of the vaginal flora are increased by the patient's assessment of her discharge. None of the clinic patients had sought advice for a discharge. On direct questioning $55 \%$ considered they had a discharge in excess of what the patient considered 'normal'. This was confirmed by examination in only 11 patients, $3.8 \%$ of the total population studied, and from these a microbiological cause for the discharge was demonstrated in less than half.

We wish to thank Dr. June Davy and Dr. Mary Farr for clinical assistance, Miss E. H. L. Duncan (Statistics) and Miss M. P. English (yeast identification) for invaluable advice, and Dr. H. R. Cayton for encouragement and ready counsel. 


\section{REFERENCES}

Catterall, R. D. (1966). Lancet, 2, 830.

Census (1961). Classification of Occupations.

Cooper, K. E., Mayr-Harting, A., and McLachlan, A. E. W. (1950). Brit. J. vener. Dis., 26, 16.

Cruickshank, R., and Sharman, A. (1934). J. Obstet. Gynaec. Brit. Emp., 41, 190, 369.

Davis, M. E., and Pearl, S. A. (1938). Amer. J. Obstet. Gynec., 35, 77.

Liston, W. G., and Cruickshank, L. G. (1940). Edinb. med. J., 47, 369.
Morison, C. R. (1966). Brit. med. J., 1, 291.

Porter, P. S., and Lyle, J. S. (1966). Arch. Derm., 93, 402.

Ramsay, A. M., and Gillespie, M. (1941). J. Obstet. Gynaec. Brit. Emp., 48, 569.

Rosenthal, A. H., and Stone, F. M. (1940). J. Amer. med. Ass., 114, 840.

Stenton, P. (1957). J. med. Lab. Technol., 14, 228.

Taschdjian, C. L., Burchall, J. J., and Kozinn, P. J. (1960). Amer. J. Dis. Child., 99, 212

Yaffee, H. S., and Grots, I. (1965). New Engl. J. Med., 272, 647. 